\title{
Protection from vascular endothelial dysfunction in acute glycemic load-induced primary hypertension by vitamin $\mathrm{C}$ and $\mathrm{E}$
}

\author{
J.X. Xu' ${ }^{1,2}$ L. Su ${ }^{3}$ L. Chen ${ }^{3}$ and J.X. Lin $^{3}$ \\ ${ }^{1}$ Department of Geratology Fuzhou General Hospital of Nanjing Command, \\ PLA, Fuzhou, Fujian, China \\ ${ }^{2}$ Department of Geratology, Fuzhou General Hospital, Fujian Medical University, \\ Fuzhou, Fujian, China \\ ${ }^{3}$ Institute of Hypertension, \\ The First Clinical Medical College of Fujian Medical University, \\ Fuzhou, Fujian, China \\ Corresponding author: J.X. Lin \\ E-mail: jinxiulincn@163.com
}

Genet. Mol. Res. 13 (3): 7246-7255 (2014)

Received June 3, 2013

Accepted June 30, 2014

Published September 5, 2014

DOI http://dx.doi.org/10.4238/2014.September.5.9

\begin{abstract}
This study aimed to investigate the influence of acute glycemic load on vascular endothelial function in patients with hypertension and to evaluate the protective effect of vitamins $\mathrm{C}$ and $\mathrm{E}$ during the acute glycemic phase. We randomly selected 39 hypertensive patients and 21 normal subjects and divided them into 3 groups: $75 \mathrm{~g}$ oral glucose (glycemic load group), $75 \mathrm{~g}$ glucose $+0.9 \mathrm{~g}$ vitamin $\mathrm{C}$ (VC group), $75 \mathrm{~g}$ glucose $+2 \mathrm{~g}$ vitamin $\mathrm{C}+0.8 \mathrm{~g}$ vitamin $\mathrm{E}(\mathrm{VC}+\mathrm{VE}$ group). Extravascular color Doppler ultrasound was used to detect brachial artery flow-mediated vasodilation at $0,1,2$, and $3 \mathrm{~h}$, and, at the same time, serum anti-oxidant products were measured. Basic endothelial functions in patients with hypertension were decreased in the glycemic load group $(9.48 \pm 3.33$ versus $13.09 \pm 6.78 \%$, $\mathrm{P}<0.05)$, and was even more depressed in the hypertensive group $(9.48 \pm$ 3.33 versus $14.20 \pm 6.48 \%, \mathrm{P}<0.05)$. Antioxidant vitamins played a dose-
\end{abstract}


dependent protective role on acute damage of endothelial function due to glycemic load. Acute high blood sugar damaged vascular endothelial functions, especially in hypertensive patients, but this effect can be reversed by large doses of vitamin $\mathrm{C}$ and $\mathrm{E}$.

Key words: Vitamin C; Vitamin E; Endothelium-dependent vasodilation; Primary hypertension; Acute glucose load

\section{INTRODUCTION}

High blood pressure is one of the major risk factors for cardiovascular events, which are not only caused by hemodynamic abnormalities, but are also associated with a variety of metabolic disorders, such as insulin resistance (Anfossi et al., 2009), low high-density lipoprotein hyperlipidemia, hypertriglyceridemia (Ansell, 2005), uricemia, and obesity. These multiple risk factors often have gathered tendencies and synergize to accelerate the emergence and progression of hypertension complications. However, impairment of vascular endothelial function is the initiating factor. Vascular endothelial cell dysfunction can aggravate a variety of pathological states through the release of various vasoactive substances (Watanabe et al., 2006; Shreenivas and Oparil, 2007; Matchar et al., 2008), and aggravates the condition of individuals with epidemiological factors for cardiovascular disease, such as hypertension, hyperglycemia, and dyslipidemia.

It is an indisputable fact that sustained hyperglycemia can impair vascular endothelial function. In a comprehensive study, Willams et al. (1998) proposed that transient hyperglycemia in blood circulation also can damage normal vascular endothelial cell function. Preliminary results from our study showed that hypertension in patients is always accompanied by significant vascular endothelial dysfunction, and postprandial hypertriglyceridemia increased damage to vascular endothelial cells in patients with hypertension (Funada et al., 2002). Therefore, we considered whether and how acutely increased glucose loads will initiate or further aggravate the damage of vascular endothelial cell function in patients with hypertension. We also considered whether acutely increased glucose load-induced endothelial dysfunction could be inhibited by drug intervention. The postprandial metabolic dynamic changes in the body persist at most times throughout the day, so the glycolipid changes in the postprandial stage are crucial to the progress of atherosclerosis (Parks, 2001; Kolovou et al., 2005). Therefore, it is essential to study whether postprandial transient hyperglycemia has an adverse effect on non-diabetic patients with hypertension and normal vascular endothelial function, to elucidate the possible mechanism of adverse impact and to determine how to avoid such adverse effects.

Previous research showed that acute hyperglycemia damages vascular endothelial function through oxidative stress (Mah and Bruno, 2012), damaging cells by destroying the balance of oxidants and antioxidants. The released oxidizing agents in oxidative stress include a variety of free radicals, also known as reactive oxygen species (ROS). Meanwhile, oxidative stress can be increased due to decreased antioxidant levels, thus exacerbating damage to the body. Therefore, in the absence of antioxidant, the fulcrum in the peroxidant-antioxidant balance shifts towards promoting endothelial damage. Moreover, antioxidant treatment to restore the balance of the oxidation-antioxidant system in vivo is an important strategy used to prevent and treat vascular endothelial damage. Although large-scale clinical data showed that vitamin E treatment did not reduce the incidence of cardiovascular and cerebrovascular disease, other 
studies have shown that vitamin $\mathrm{C}$ and $\mathrm{E}$ have a protective effect on the vascular endothelium by reducing oxidative damage (Rodrigo et al., 2008). The purpose of this study was to investigate whether this protective effect in acute hyperglycemia exists and is related to the dose.

\section{MATERIAL AND METHODS}

\section{Subjects}

Subjects were chosen from newly diagnosed patients at our clinic from October 2002 to June 2003. Our cohort comprised 39 patients with essential hypertension (EH), including 18 males and 21 females aged $49 \pm 11$ years old, who were diagnosed with hypertension at the $122 \mathrm{nd}$ level after $24 \mathrm{~h}$ of ambulatory blood pressure monitoring. As controls, we enrolled 21 patients who had no hypertension, including 8 males and 13 females aged $46.1 \pm 10.2$ years old, without a family history of hypertension. Consent from all patients was acquired. The two groups were chosen in accordance with the following exclusion criteria: 1) no history of coronary heart disease, diabetes, and abnormal glucose tolerance, or the diseases of the thyroid, liver, kidneys, or pancreas; 2) no chronic wasting disease or malignant tumors; 3 ) no consumption of antihypertensive, hypoglycemic, or lipid drugs; no consumption of drugs from 5 days before the experiment; no smoking, drinking, or high-fat food consumption from $12 \mathrm{~h}$ before the experiment; no taking estrogen for postmenopausal women; and 4) a fasting serum total cholesterol (TC) $<5.20 \mathrm{mM}$; triglycerides (TG) $<1.7 \mathrm{mM}$; high-density lipoprotein cholesterol (HDL-C) is between 0.89 to $2.00 \mathrm{mM}$; LDL-C $<3.36 \mathrm{mM}$; uric acid $<416 \mathrm{mM}$. The subjects who met these criteria were randomly divided into 3 groups: patients in the glucose load group took $75 \mathrm{~g}$ glucose orally; patients in the vitamin $\mathrm{C}$ and $\mathrm{E}$ group took $75 \mathrm{~g}$ glucose, $2 \mathrm{~g}$ vitamin $\mathrm{C}$, and $0.8 \mathrm{~g}$ vitamin E orally; and patients in the vitamin C group took $75 \mathrm{~g}$ glucose and $0.9 \mathrm{~g}$ vitamin C orally. The height, weight, and blood pressure of all subjects were measured before the experiment by the same person (blood pressure measurements were the average of 3 readings taken at each time point), and the body mass index (BMI) was calculated. The age, history of smoking (more than 5 per day for 5 consecutive years), history of alcohol consumption (at least $50 \mathrm{~g}$ alcohol per day for more than 5 years), and family history of hypertension were in the questionnaire.

\section{Oral glucose tolerance test and insulin sensitivity detection}

After fasting for $12 \mathrm{~h}$, the subjects took $75 \mathrm{~g}$ glucose orally and $2 \mathrm{~mL}$ blood samples were taken at 60,120, and 180 min before the trial. Blood glucose was detected with the oxidase-peroxidase method with the same HITACH2170A automatic biochemical analyzer under the optimum conditions. Insulin was detected by radioimmunoassay with the same SN2682 RIA $\gamma$-Counter (the Environment Instrument Factory of Institute of Atomic Energy in Shanghai) in the Nuclear Medicine Division of our hospital under optimal conditions. Kits were supplied by the China Institute of Atomic Energy. The Uniform Laboratory Code for the Ministry of Health was 125006 . The serum No. of National valued quality control was 15111P15112.

\section{Detection of endothelium-dependent vasodilation function}

Endothelial-dependent vasodilation function in the study subjects was detected at the fast- 
ing state and at 1,2, and $3 \mathrm{~h}$ after $75 \mathrm{~g}$ oral glucose in order to assess dynamic changes. The entire ultrasound detection procedure was conducted by an experienced specialist doctor who had no knowledge of the study using the LOGIQ7 color Doppler ultrasound diagnosis system (General Electric, Fairfield, CT, USA). A 7-MHz line array probe was used that simultaneously recorded the ECG. The room temperature of darkroom was maintained at $22^{\circ} \mathrm{C}$ to $23^{\circ} \mathrm{C}$. Subjects were kept supine, with the right arm outreached at $15^{\circ}$ and its palm up. A 5-cm segment of the brachial artery in the right elbow was selected as the target vessel. After $10 \mathrm{~min}$ of rest, the longitudinal section was imaged by 2-dimensional ultrasound imaging scanning. When the intima of the artery anterior and posterior wall could be visualized most clearly, the gain was adjusted until the lumen interface could be identified. The distance between the anterior and posterior intima of the brachial artery was measured during the ventricular end-diastolic (synchronization electrocardiogram showed an $\mathrm{R}$ wave). Three cycles were measured at a time and the average value was used. This study was designed to set the mean of twice-measured inner diameter of the brachial artery under the resting state as a basic value (D0). Then, the 5-17.5-cm section on the right elbow was tied to the width of a $12.5-\mathrm{cm}$ cuff, which was connected to a HOKANSON vascular function pressure system (Hokanson, E220 rapid Cuff Inflator, AG2101 Cuff Inflation air resource; Bellevue, WA, USA). This machine rapidly pressurized to $200 \mathrm{~mm} \mathrm{Hg}$ for $5 \mathrm{~min}$, and then rapidly reduced pressure to $0 \mathrm{~mm} \mathrm{Hg}$. The inner diameter of the brachial artery (D1) was measured separately when the pressure declined to $0 \mathrm{~mm} \mathrm{Hg}$ and measured again after $60 \mathrm{~s}$. During the testing process, the ultrasound probe was always maintained in a fixed position. Each brachial artery diameter measurement was taken at the same position. Changes in brachial artery diameter after reactive hyperemia were presented along with the percentage of the baseline value from the first measurement: (D1 - D0) / D0 x 100\%, which indicated endotheliumdependent flow-mediated vasodilation (Park et al., 2001; Virdis and Taddei, 2011) (EDF). The reproducibility of this method has been verified at our institute. To analyze feasibility and reliability, the same vessel segments (brachial artery segments) from 15 normal adults were repeatedly measured at different time points. For the same vessel segment, an inspector was single-blinded to check results; technical error $=$ the absolute value (the first measured value - the second measured value) / [(the first measured value + second measured value) / 2]; the calculated intra-observer error was $0.94 \%$. The measured images were recorded and analyzed by 2 experienced observers in double-blinded conditions; the calculated intra-observer error was $2.45 \%$. Vascular endothelial function was repeatedly measured at the 4 time points of glycemic load, that is, $0,1,2$, and $3 \mathrm{~h}$ after oral glucose intake.

\section{Determination of serum antioxidant products}

We collected $5 \mathrm{~mL}$ venous blood after $75 \mathrm{~g}$ oral glucose at the 4 time points to assess glucose load, that is, $0,1,2$, and $3 \mathrm{~h}$ after oral glucose. Blood samples were placed in a $37^{\circ} \mathrm{C}$ water bath for $45 \mathrm{~min}$, and then centrifuged at $3500 \mathrm{rpm}$ for $10 \mathrm{~min}$ at $4^{\circ} \mathrm{C}$ to separate the serum in order to determine superoxide dismutase (SOD), total antioxidant capacity (T-AOC), and antisuperoxide anion radical $\left(\mathrm{O}_{2}^{-}\right)$levels. All specimens were stored at $-20^{\circ} \mathrm{C}$ and processed batches were measured later. The kit was supplied by Nanjing Jiancheng Bioengineering Co., Ltd.

\section{Statistics}

In this study, the SPSS statistical package was used to process data. Measurement data are reported as means $\pm \mathrm{SD}$. A paired Student $t$-test was used to compare the same group at different 
time points. A grouped Student $t$-test was used to compare the different treatment groups. A oneway ANOVA test was used for multiple group comparisons. We defined differences for which $\mathrm{P}<$ 0.05 was considered to be statistically significant. $\mathrm{P}<0.01$ indicates a very significant difference.

\section{RESULTS}

\section{A general comparison of the different treatment groups}

There were no significant differences between groups by age, body mass index (BMI), TG, TC, LDLC, HDLC, or uric acid. However, systolic and diastolic blood pressure between hypertensive and normal subjects showed a significant difference (Table 1).

Table 1. Comparison of general clinical characters among all groups.

\begin{tabular}{|c|c|c|c|c|c|c|}
\hline \multirow[t]{2}{*}{ Stem } & \multicolumn{2}{|c|}{ Glycemic load group } & \multicolumn{2}{|c|}{$\mathrm{VC}+\mathrm{VE}$ group } & \multicolumn{2}{|c|}{$\mathrm{VC}$ group } \\
\hline & Hypertension & Control & Hypertension & Control & Hypertension & Control \\
\hline Case & 13 & 7 & 13 & 7 & 13 & 7 \\
\hline Age & $46.5 \pm 9.3$ & $44.0 \pm 7.4$ & $51.1 \pm 10.5$ & $46.9 \pm 9.9$ & $49.9 \pm 14.7$ & $43.4 \pm 7.4$ \\
\hline BMI $\left(\mathrm{kg} / \mathrm{m}^{2}\right)$ & $25.8 \pm 3.4$ & $24.1 \pm 4.6$ & $24.3 \pm 2.3$ & $24.8 \pm 2.7$ & $23.5 \pm 2.8$ & $24.0 \pm 2.1$ \\
\hline $\mathrm{SP}(\mathrm{mmHg})$ & $150 \pm 9^{a}$ & $128 \pm 6$ & $142 \pm 14^{\mathrm{a}}$ & $121 \pm 12$ & $154 \pm 12^{\mathrm{a}}$ & $124 \pm 6$ \\
\hline $\mathrm{DP}(\mathrm{mmHg})$ & $95 \pm 7^{\mathrm{a}}$ & $79 \pm 6$ & $89 \pm 6^{\mathrm{a}}$ & $76 \pm 5$ & $94 \pm 11^{\mathrm{a}}$ & $84 \pm 3$ \\
\hline $\mathrm{TC}(\mathrm{mM})$ & $5.15 \pm 1.18$ & $4.46 \pm 0.87$ & $5.13 \pm 0.76$ & $4.42 \pm 0.60$ & $4.74 \pm 0.73$ & $4.28 \pm 1.48$ \\
\hline TG (mM) & $1.57 \pm 0.51$ & $1.25 \pm 0.49$ & $1.70 \pm 0.49$ & $1.30 \pm 0.47$ & $1.67 \pm 0.42$ & $1.57 \pm 0.68$ \\
\hline LDL (mM) & $2.57 \pm 0.89$ & $2.50 \pm 0.59$ & $3.12 \pm 0.61$ & $2.11 \pm 0.72$ & $2.70 \pm 0.51$ & $2.60 \pm 0.71$ \\
\hline HDL (mM) & $1.30 \pm 0.37$ & $1.37 \pm 0.40$ & $1.53 \pm 0.39$ & $1.67 \pm 0.68$ & $1.30 \pm 0.27$ & $1.25 \pm 0.45$ \\
\hline Uric acid $(\mu \mathrm{M})$ & $368 \pm 86.8$ & $327 \pm 46$ & $337 \pm 59$ & $328 \pm 86$ & $354 \pm 42$ & $350 \pm 58$ \\
\hline
\end{tabular}

$\mathrm{BMI}=$ body mass index $\mathrm{SP}=$ systolic blood pressure; $\mathrm{DP}=$ diastolic blood pressure $; \mathrm{TC}=$ total cholesterol; $\mathrm{TG}=$ triglyceride; $\mathrm{LDL}=$ low density lipoprotein; $\mathrm{HDL}=$ high density lipoprotein. ${ }^{\mathrm{a}} \mathrm{P}<0.05$, compared with control group.

\section{Effect of acute glycemic load on vascular function}

Compared with normal controls, endothelium-dependent vasodilation in 39 cases of high blood pressure decreased at the fasting state $(15.19 \% \pm 5.12 \%$ versus $13 \% \pm 5.28 \%, \mathrm{P}>$ $0.05)$, but did not reach statistical significance. After oral glucose (75 g) administration, endothelial function of hypertensive and normal subjects were obviously damaged, and hypertensive patients showed more significant changes when compared with normal controls. Such damage returned to normal at 1 and $2 \mathrm{~h}$ after oral glucose intake. Endothelial function in hypertensive patients and normal subjects showed no significant damage after $75 \mathrm{~g}$ oral glucose intake combined with $2.0 \mathrm{~g}$ vitamin $\mathrm{C}$ and $0.8 \mathrm{~g}$ vitamin $\mathrm{E}$. While the endothelial function in hypertensive patients and normal subjects decreased slightly more than the $0.9 \mathrm{~g}$ vitamin $\mathrm{C}$ group, the difference did not reach the level of statistical significance. For hypertensive patients in different treatment groups, compared with the glycemic load group, the EDF of the oral glucose vitamin $\mathrm{C}$ and $\mathrm{E}$ group and vitamin $\mathrm{C}$ group both showed significant improvements $(\mathrm{P}<0.05)$ under the conditions for which endothelial function showed no significant difference $(P>0.05)$ at $1 \mathrm{~h}$ after taking glucose, especially for the vitamin $\mathrm{C}$ and $\mathrm{E}$ group (Table 2).

\section{Dynamic changes in superoxide anion radical concentration in the 3 groups}

There was no significant difference in serum anti-superoxide anion radical $\left(\mathrm{O}_{2}^{-}\right)$levels 
in the 3 groups at the fasting state $(\mathrm{P}>0.05) . \mathrm{O}_{2}^{-}$levels were significantly reduced in the glycemic load group at $1 \mathrm{~h}$ after oral glucose compared to the fasting state $(\mathrm{P}<0.05)$. $\mathrm{O}_{2}^{-}$levels were also increased in the vitamin $\mathrm{C}$ and $\mathrm{E}$ group compared to the fasting state $(\mathrm{P}<0.05)$; the vitamin $\mathrm{C}$ group was increased, but the difference was not statistically significant $(\mathrm{P}>0.05)$; $\mathrm{O}_{2}^{-}$levels in the vitamin $\mathrm{C}$ and $\mathrm{E}$ group were significantly higher at $1 \mathrm{~h}$ than in the glycemic load group $(\mathrm{P}<0.05)$ (Table 3$)$.

Table 2. Comparison of endothelial flow-mediated dilation between essential hypertension group and controls.

\begin{tabular}{|c|c|c|c|c|c|c|}
\hline \multirow[t]{2}{*}{ Stem } & \multicolumn{2}{|c|}{ Glycemic load group } & \multicolumn{2}{|c|}{$\mathrm{VC}+\mathrm{VE}$ group } & \multicolumn{2}{|c|}{ VC group } \\
\hline & Hypertension (\%) & Control (\%) & Hypertension (\%) & Control (\%) & Hypertension (\%) & Control (\%) \\
\hline Empty stomach & $13.1 \pm 6.8$ & $17.9 \pm 6.9$ & $16.9 \pm 5.1$ & $17.1 \pm 3.8$ & $14.6 \pm 2.3$ & $116.0 \pm 5.1$ \\
\hline $1 \mathrm{~h}$ after oral glucose & $9.5 \pm 3.3^{\mathrm{ac}}$ & $14.2 \pm 6.5^{\mathrm{c}}$ & $17.2 \pm 4.8^{\mathrm{e}}$ & $17.8 \pm 5.2$ & $13.1 \pm 3.2^{\mathrm{e}}$ & 14. \pm 5.4 \\
\hline $2 \mathrm{~h}$ after oral glucose & $12.0 \pm 6.8$ & $17.6 \pm 6.8$ & $17.2 \pm 4.8$ & $17.4 \pm 4.4$ & $14.4 \pm 2.3$ & $15.6 \pm 4.4$ \\
\hline $3 \mathrm{~h}$ after oral glucose & $13.1 \pm 6.0$ & $17.6 \pm 6.8$ & $17.4 \pm 5.0$ & $17.4 \pm 4.4$ & $14.4 \pm 2.3$ & $16.0 \pm 5.1$ \\
\hline
\end{tabular}

a $\mathrm{P}<0.05$, compared with the control group on the same treatment group; ${ }^{\mathrm{P}}<0.05$, compared with empty endothelium-dependent flow (EDF) of the same treatment group; ${ }^{e} \mathrm{P}<0.05$, compared with EDF of the same glucose load group at the same moment.

Table 3. Comparison of the plasma concentration of $\mathrm{O}_{2}$ among the different groups at the different time.

\begin{tabular}{|c|c|c|c|}
\hline Time & Glucose load group (U/L) & $\mathrm{VC}+\mathrm{VE}$ group (U/L) & VC group (U/L) \\
\hline $0 \mathrm{~h}$ & $218.5 \pm 75.2$ & $232.4 \pm 67.4$ & $216.0 \pm 49.6$ \\
\hline $1 \mathrm{~h}$ & $200.2 \pm 60.9^{\mathrm{a}}$ & $257.7 \pm 78.1^{\mathrm{ac}}$ & $223.4 \pm 60.0$ \\
\hline $2 \mathrm{~h}$ & $201.4 \pm 61.2$ & $243.3 \pm 70.6$ & $220.4 \pm 66.1$ \\
\hline $3 \mathrm{~h}$ & $203.5 \pm 72.7$ & $232.4 \pm 69.8$ & $209.3 \pm 55.4$ \\
\hline
\end{tabular}

\section{Changes in serum superoxide dismutase concentrations in different treatment groups before and after oral glucose}

There was no significant difference in serum superoxide dismutase (SOD) levels in the 3 groups at the fasting state $(\mathrm{P}>0.05)$. SOD levels were significantly lower in the glycemic load group at $1 \mathrm{~h}$ after oral glucose intake than at the fasting state $(90.6 \pm 28.1$ versus $81.7 \pm$ $30.1 \mathrm{kU} / \mathrm{L}, \mathrm{P}<0.05)$. SOD levels in the vitamin $\mathrm{C}$ group were somewhat reduced, but did not reach statistical significance $(87.0 \pm 14.0$ versus $75.9 \pm 13.9 \mathrm{kU} / \mathrm{L}, \mathrm{P}>0.05)$; SOD levels in the vitamin $\mathrm{C}$ and $\mathrm{E}$ group were higher than at the fasting state, which was significantly higher than in the glycemic load group $(93.7 \pm 21.2$ versus $81.7 \pm 30.1 \mathrm{kU} / \mathrm{L}, \mathrm{P}<0.05)$ (Table 4$)$.

$\begin{aligned} & \text { Table 4. Comparison of the plasma concentration of superoxide dismutase among the different groups at the } \\
& \text { different times. }\end{aligned}$
\begin{tabular}{lccc}
\hline Time & Glucose load group $(\mathrm{kU} / \mathrm{L})$ & $\mathrm{VC}+\mathrm{VE}$ group $(\mathrm{kU} / \mathrm{L})$ & $\mathrm{VC}$ group $(\mathrm{kU} / \mathrm{L})$ \\
\hline $0 \mathrm{~h}$ & $90.6 \pm 28.1$ & $90.1 \pm 16.3$ & $87.0 \pm 14.0$ \\
$1 \mathrm{~h}$ & $81.7 \pm 30.1^{\mathrm{a}}$ & $93.7 \pm 21.2^{\mathrm{c}}$ & $75.9 \pm 13.9$ \\
$2 \mathrm{~h}$ & $88.9 \pm 34.2$ & $91.0 \pm 16.3$ & $75.4 \pm 14.5$ \\
$3 \mathrm{~h}$ & $80.5 \pm 35.2$ & $91.0 \pm 22.5$ & $74.7 \pm 10.6$ \\
\hline a $<0.05$, compared with oh on the same treatment group; ${ }^{\mathrm{C}} \mathrm{P}<0.05$, compared with the glucose load group at the
\end{tabular}
same moment. Data are reported as means $\pm \mathrm{SD}$.




\section{Changes in total serum antioxidant capacity in different treatment groups before and after oral glucose intake}

There were no significant differences in total serum antioxidant capacity (T-AOC) in the three different treatment groups at the fasting state $(\mathrm{P}>0.05)$. The T-AOC was lower in the glucose load group at $1 \mathrm{~h}$ after oral glucose compared to the fasting state $(10.84 \pm 2.82$ versus 10.23 $\pm 2.22 \mathrm{kU} / \mathrm{L})$, but this difference did not reach the level of statistical significance $(\mathrm{P}>0.05)$. The $\mathrm{T}-\mathrm{AOC}$ in the vitamin $\mathrm{C}$ and $\mathrm{E}$ group was higher than at the fasting state $(11.37 \pm 2.71$ versus $12.96 \pm 3.70 \mathrm{kU} / \mathrm{L}, \mathrm{P}<0.05)$. The T-AOC in the vitamin $\mathrm{C}$ group increased $(9.90 \pm 4.86$ versus $11.19 \pm 2.14 \mathrm{kU} / \mathrm{L})$, but this difference did not reach statistical difference $(\mathrm{P}>0.05)$. The T-AOC in the vitamin $\mathrm{C}$ and $\mathrm{E}$ group was significantly higher than in the glucose load group at $1 \mathrm{~h}$ after oral glucose intake $(12.96 \pm 3.70$ versus $10.23 \pm 2.22 \mathrm{kU} / \mathrm{L}, \mathrm{P}<0.05)$ (Table 5).

Table 5. Comparison of the plasma concentration of T-AOC among the different groups at the different time.

\begin{tabular}{|c|c|c|c|}
\hline Time & Glucose load group (kU/L) & $\mathrm{VC}+\mathrm{VE}$ group $(\mathrm{kU} / \mathrm{L})$ & $\mathrm{VC}$ group $(\mathrm{kU} / \mathrm{L})$ \\
\hline$\overline{0 \mathrm{~h}}$ & $10.8 \pm 2.8$ & $11.4 \pm 2.7$ & $9.9 \pm 4.9$ \\
\hline $1 \mathrm{~h}$ & $10.2 \pm 2.2$ & $13.0 \pm 3.7^{\mathrm{ac}}$ & $11.2 \pm 2.1$ \\
\hline $2 \mathrm{~h}$ & $10.8 \pm 4.4$ & $11.8 \pm 2.9$ & $10.7 \pm 2.6$ \\
\hline $3 \mathrm{~h}$ & $9.9 \pm 4.5$ & $12.1 \pm 4.9$ & $11.0 \pm 3.3$ \\
\hline
\end{tabular}

\section{DISCUSSION}

The vascular endothelium is a very active and versatile endocrine organ. Its dysfunction is a common feature that contributes to many cardiovascular diseases. Impaired endothelium-dependent vasodilation is the most detrimental type of endothelial cell dysfunction (Raitakari and Celermajer, 2000), which occurs prior to the formation of atherosclerosis, exists throughout the entire process, and is present in a variety of cardiovascular diseases, such as hypertension (Iiyama et al., 1996; Taddei et al., 1998), diabetes (Khder et al., 1998), chronic heart failure (Drexler, 1998), and others. Many studies have shown that there is an underlying decline of endothelium-dependent diastolic function and an increase of endothelium-dependent contractile function in hypertension patients or established hypertensive animal models, almost without exception (Celermajer et al., 1992). The pathophysiological mechanism is as follows: the interaction of long-term high blood pressure induces increased vascular wall tension and blood flow shear stress that can cause endothelial cell damage, which significantly reduces the secretion of vascular relaxation substances, such as NO, and significantly increases the abundance of vasoconstrictor substances, such as endothelin (ET) (Hedner and Sun, 1997); next, the self-regulation system based on the ET/NO balance in vivo becomes damaged (Drexler and Hornig, 1999). The direct presentation reduces blood flow-dependent arterial diastolic function. Similarly, in our study, we can see that the foundation of endothelial function in the patients in each treatment group with hypertension showed a downward trend compared with the control group, but it failed to reach the level of statistical difference due to the small sample size. Vascular endothelial dysfunction is the initiating factor of hypertension-dependent target organ damage and complications (Higashi et al., 2012). 
Previous studies have shown that chronic hyperglycemia can directly or indirectly cause and aggravate endothelial cell injury through a variety of mechanisms (Tesfamariam, 1994; Ohara et al., 1995; Nishio and Watanabe, 1996). An acute glycemic load can also induce transiently decreased vascular endothelial function (Ceriello et al., 2002). Tests conducted in vitro confirmed that the intake of large amounts of sugar can cause free radical-mediated damage of endothelial function (Tesfamariam and Cohen, 1992). These in vivo tests also confirmed that in normal people after OGTT load, the levels of serum thrombin fragment increased and then returned to normal after the application of antioxidants or glutathione, suggesting that acute hyperglycemia causes this damage through the oxidative stress pathway (Kawano et al., 1999). Lacroix et al. (2012) thought that oxidative stress plays an important role in postprandial endothelial dysfunction. Our study clearly demonstrates that an acute glycemic load can cause transient vascular endothelial damage in both normal subjects and patients with hypertension. Such damage peaked approximately $1 \mathrm{~h}$ after the glycemic load, and its magnitude is more severe in hypertensive patients. Thus, endothelial function can act as a hub that links a variety of risk factors for cardiovascular and cerebrovascular diseases. Acute hyperglycemia in normal individuals can induce vascular endothelial injury and is the initiating event for atherosclerosis. Repeated episodes of acute hyperglycemia have a cumulative effect and, when consequences of its accumulation are sustained, widespread vascular endothelial damage occurs. The enhanced role of oxidative stress is an important link with acute hyperglycemiainduced endothelial injury. Inhibition of oxidative stress may represent one of the most important strategies for hypertension prevention and treatment.

Large doses of antioxidant vitamins can effectively ameliorate vascular endothelial dysfunction and reduce the incidence of cardiovascular events. This statement is supported by clear results from a large-scale clinical trial-heart prevention study (HPS) conducted by Oxford University (Gerstein, 1997). The antioxidants vitamin C (Chen et al., 1996; Takagi and Shimamoto, 2001; Frayn, 2002) and vitamin E (Celermajer et al., 1992; Iiyama et al., 1996) can eliminate this negative effect through a variety of mechanisms: direct inhibition of hyperglycemia-mediated release of superoxide anion; competitive binding with superoxide anion, which can prevent NO inactivation; inhibition of LDL oxidation, which can also directly inactivate NO; and direct promotion of NO synthase activity and NO synthesis (Gerstein and Yusuf, 1996). However, experiments showed that antioxidants are transported into cells in a time-dependent manner. It is impossible to alter NO synthase activity at $1 \mathrm{~h}$ after glucose intake. Therefore, this mechanism did not play a major role in our study. The present study did not carefully differentiate the effects of vitamin $C$ versus vitamin E. However, theoretically, we believe that there was a synergy between these 2 vitamins (Raitakari and Celermajer, 2000). Through observing its positive effects on endothelial function by using different doses of vitamin C, the results showed that low-dose vitamin C could partially improve endothelial function. In vivo, the speed of super oxygen anion reactivity with NO is greater than that of antioxidant superoxide anion. Therefore, it is necessary to increase the antioxidant concentration to improve the binding capacity with NO (Tsikas et al., 2012; Wray et al., 2012).

The tests carried out in vivo and in vitro confirmed that an acute glycemic load can cause acute damage of endothelial function, which may be related to the increased concentration of adhesion molecules, hyperthyroidism of coagulation, oxidative stress, or other mechanisms. Our series of studies has also found that transient damage to vascular endothelial function in hypertensive patients is accompanied with more severe insulin resistance. Whether 
insulin resistance played a certain role in the damage to vascular endothelial function is worth further exploration. Due to the limitations of research time and money, our study mainly focused on oxidative stress hyperthyroidism in order to find a simple antioxidant measurement. Another shortcoming was that we were unable to detect the concentration of basic plasma vitamin $\mathrm{C}$ and $\mathrm{E}$ in our subjects, which limits our understanding of the possible change of vascular endothelial function in patients who were deficient in vitamin C or E. Doses of vitamin $\mathrm{C}$ and $\mathrm{E}$ were decided based on the results of previous studies; a high-dose combination was chosen. Our study did not include subgroups treated with different doses in order to observe their efficacy, which has some limitations for clinical application.

In summary, vascular endothelial function in hypertensive patients showed a downward trend compared with normal subjects. However, acute hyperglycemia may further damage endothelial function of hypertensive patients and even normal subjects through a variety of pathways, such as oxidative stress. The antioxidants vitamin $\mathrm{C}$ and $\mathrm{E}$ can temporarily reverse this damage and play roles in the immediate protection of endothelial function.

\section{REFERENCES}

Anfossi G, Russo I, Doronzo G and Trovati M (2009). Contribution of insulin resistance to vascular dysfunction. Arch. Physiol. Biochem. 115: 199-217.

Ansell BJ (2005). Evidence for a combined approach to the management of hypertension and dyslipidemia. Am. J. Hypertens. 18: 1249-1257.

Celermajer DS, Sorensen KE, Gooch VM, Spiegelhalter DJ, et al. (1992). Non-invasive detection of endothelial dysfunction in children and adults at risk of atherosclerosis. Lancet 340: 1111-1115.

Ceriello A, Taboga C, Tonutti L, Quagliaro L, et al. (2002). Evidence for an independent and cumulative effect of postprandial hypertriglyceridemia and hyperglycemia on endothelial dysfunction and oxidative stress generation: effects of short- and long-term simvastatin treatment. Circulation 106: 1211-1218.

Chen D, Lin J and Zeng K (1996). Obesity may have more pronounced effect on the occurrence of insulin resistance than hypertension. Zhonghua Yi Xue Za Zhi 76: 519-523.

Drexler H (1998). Hypertension, heart failure, and endothelial function. Am. J. Cardiol. 82: 20S-22S.

Drexler H and Hornig B (1999). Endothelial dysfunction in human disease. J. Mol. Cell. Cardiol. 31: 51-60.

Frayn KN (2002). Insulin resistance, impaired postprandial lipid metabolism and abdominal obesity. A deadly triad. Med. Princ. Pract. 11 Suppl. 2: 31-40.

Funada J, Sekiya M, Hamada M and Hiwada K (2002). Postprandial elevation of remnant lipoprotein leads to endothelial dysfunction. Circ. J. 66: 127-132.

Gerstein HC (1997). Glucose: a continuous risk factor for cardiovascular disease. Diabet. Med. 14 (Suppl 3): S25-S31.

Gerstein HC and Yusuf S (1996). Dysglycaemia and risk of cardiovascular disease. Lancet 347: 949-950.

Hedner T and Sun X (1997). Measures of endothelial function as an endpoint in hypertension? Blood Press. 2: 58-66.

Higashi Y, Kihara Y and Noma K (2012). Endothelial dysfunction and hypertension in aging. Hypertens. Res. 35: 10391047.

Iiyama K, Nagano M, Yo Y, Nagano N, et al. (1996). Impaired endothelial function with essential hypertension assessed by ultrasonography. Am. Heart J. 132: 779-782.

Kawano H, Motoyama T, Hirashima O, Hirai N, et al. (1999). Hyperglycemia rapidly suppresses flow-mediated endothelium-dependent vasodilation of brachial artery. J. Am. Coll. Cardiol. 34: 146-154.

Khder Y, Briancon S, Petermann R, Quilliot D, et al. (1998). Shear stress abnormalities contribute to endothelial dysfunction in hypertension but not in type II diabetes. J. Hypertens. 16: 1619-1625.

Kolovou GD, Anagnostopoulou KK, Daskalopoulou SS, Mikhailidis DP, et al. (2005). Clinical relevance of postprandial lipaemia. Curr. Med. Chem. 12: 1931-1945.

Lacroix S, Rosiers CD, Tardif JC and Nigam A (2012). The role of oxidative stress in postprandial endothelial dysfunction. Nutr. Res. Rev. 25: 288-301.

Mah E and Bruno RS (2012). Postprandial hyperglycemia on vascular endothelial function: mechanisms and consequences. Nutr. Res. 32: 727-740.

Matchar DB, McCrory DC, Orlando LA, Patel MR, et al. (2008). Systematic review: comparative effectiveness of 
angiotensin-converting enzyme inhibitors and angiotensin II receptor blockers for treating essential hypertension. Ann. Intern. Med. 148: 16-29.

Nishio E and Watanabe Y (1996). Glucose-induced downregulation of NO production and inducible NOS expression in cultured rat aortic vascular smooth muscle cells: role of protein kinase C. Biochem. Biophys. Res. Commun. 229: 857-863.

Ohara Y, Sayegh HS, Yamin JJ and Harrison DG (1995). Regulation of endothelial constitutive nitric oxide synthase by protein kinase C. Hypertension 25: 415-420.

Park JB, Charbonneau F and Schiffrin EL (2001). Correlation of endothelial function in large and small arteries in human essential hypertension. J. Hypertens. 19: 415-420.

Parks EJ (2001). Recent findings in the study of postprandial lipemia. Curr. Atheroscler. Rep. 3: 462-470.

Raitakari OT and Celermajer DS (2000). Flow-mediated dilatation. Br. J. Clin. Pharmacol. 50: 397-404.

Rodrigo R, Prat H, Passalacqua W, Araya J, et al. (2008). Decrease in oxidative stress through supplementation of vitamins $\mathrm{C}$ and $\mathrm{E}$ is associated with a reduction in blood pressure in patients with essential hypertension. Clin. Sci. 114: 625634.

Shreenivas S and Oparil S (2007). The role of endothelin-1 in human hypertension. Clin. Hemorheol. Microcirc. 37: 157-178.

Taddei S, Virdis A, Ghiadoni L and Salvetti A (1998). The role of endothelium in human hypertension. Curr. Opin. Nephrol. Hypertens. 7: 203-209.

Takagi S and Shimamoto K (2001). Hyperlipidemia complicated with hypertension. Nihon Rinsho 59 (Suppl 3): 738-742.

Tesfamariam B and Cohen RA (1992). Free radicals mediate endothelial cell dysfunction caused by elevated glucose. Am. J. Physiol. 263: H321-H326.

Tesfamariam B (1994). Free radicals in diabetic endothelial cell dysfunction. Free Radic. Biol. Med. 16: 383-391.

Tsikas D, Flentje M, Niemann J and Modun D (2012). Antioxidants and endothelial dysfunction in young and elderly people: is flow-mediated dilation useful to assess acute effects? Hypertension 60: e5-e7.

Virdis A and Taddei S (2011). How to evaluate microvascular organ damage in hypertension: assessment of endothelial function. High Blood Press. Cardiovasc. Prev. 18: 163-167.

Watanabe T, Kanome T, Miyazaki A and Katagiri T (2006). Human urotensin II as a link between hypertension and coronary artery disease. Hypertens. Res. 29: 375-387.

Williams SB, Goldfine AB, Timimi FK, Ting HH, et al. (1998). Acute hyperglycemia attenuates endothelium-dependent vasodilation in humans in vivo. Circulation 97: 1695-1701.

Wray DW, Nishiyama SK, Harris RA, Zhao J, et al. (2012). Acute reversal of endothelial dysfunction in the elderly after antioxidant consumption. Hypertension 59: 818-824. 